\title{
C-C chemokine-induced eosinophil chemotaxis during allergic airway inflammation
}

\author{
Nicholas W. Lukacs, Theodore J. Standiford," Stephen W. Chensue, † Robin G. Kunkel, \\ Robert M. Strieter," and Steven L. Kunkel \\ Department of Pathology and *Department of Internal Medicine, Division of Pulmonary and Critical Care, \\ University of Michigan Medical School; and + Department of Pathology and Lab Medicine, \\ The Veterans Affairs Medical Center, Ann Arbor, Michigan
}

\begin{abstract}
The production of eosinophil-specific chemotactic factors during allergic airway responses may be a pivotal event resulting in eosinophil accumulation, activation, and airway damage. Recent studies have identified specific chemokines that may play crucial roles in recruitment of eosinophils to the site of allergic reactions. In this study we have utilized an established model of schistosome egg antigen (SEA) -mediated allergic responses to examine the role of specific C-C chemokines [macrophage inflammatory protein-1 $\alpha$ (MIP-1 $\alpha$ ), RANTES, and monocyte chemoattractant protein-1 (MCP-1)] in eosinophil recruitment. We have previously identified a role for MIP-1 $\alpha$ in eosinophil accumulation in the lung and airway during allergic airway inflammation. We extend those studies using in vitro eosinophil chemotaxis to establish that both MIP-l $\alpha$ and RANTES are potent eosinophil chemotactic factors in lungs during allergic airway responses. Morphometric analysis demonstrated a peribronchial accumulation of eosinophils within the lungs beginning at $8 \mathrm{~h}$, peaking at $24 \mathrm{~h}$, and plateauing at 48-96 $\mathrm{h}$ after allergen (SEA) challenge. Utilizing whole-lung homogenates from allergen-challenged mice, in vitro eosinophil chemotactic assays demonstrated significant increases in eosinophil chemotactic activity with 8-h lung homogenates and peak activity with samples from 24-h lung homogenates. These data correlated with the morphometric analysis of peribronchial eosinophil accumulation in situ. When lung homogenates from allergen-challenged mice were preincubated in vitro with antibodies specific for MIP1a, RANTES, or MCP-1, a significant reduction in eosinophil chemotaxis was observed with only MIP-1 $\alpha$ and RANTES neutralization. Altogether, these studies indicate that RANTES and MIP-1 $\alpha$ are major eosinophil chemotactic factors produced during allergic airway responses. J. Leukoc. Biol. 60: 573-578; 1996.
\end{abstract}

Key Words: schistosome egg antigen - macrophage inflammatory protein-1 $\alpha \cdot$ monocyte chemoattractant protein-1 $\cdot$ RANTES

\section{INTRODUCTION}

Allergic pulmonary diseases affect a significant proportion of the population worldwide and include diseases such as asthma [1]. The long-term pathological effects of asthma have been attributed, in part, to infiltrating leukocytes that surround the bronchus and infiltrate into the airway [2-4]. The immune response associated with asthma has been described as having histopathological features of a chronic, cell-mediated immune reaction, characterized by the infiltration of the bronchial mucosa with neutrophils, basophils, eosinophils, macrophages, and lymphocytes [2]. Eosinophils have been reported to be the primary cell responsible for the induction of bronchial mucosal injury and are thought to induce the bronchial obstruction associated with the asthmatic response [5-14].

The elicitation of leukocyte subsets has been attributed to the production of several different chemotactic factors. Specific neutrophil, mononuclear, and eosinophil chemotactic cytokines (chemokines) have been identified. These chemoattractants have been divided into two distinct supergene families, C-X-C (alpha) and C-C (beta) chemokines $[15,16]$. These divisions have been designated by the position of the first two cysteine residues and reflect functional differences. The C-X-C family of chemokines is primarily chemotactic for neutrophils and is typified by interleukin-8 (IL-8). The C-C family of chemokines is primarily chemotactic for mononuclear phagocytes, lymphocytes, and/or eosinophils and contain closely related proteins that include monocyte chemoattractant protein-1,2,3 (MCP-1,2,3), macrophage inflammatory protein-1 $\alpha$ (MIP-1 $\alpha$ ), eotaxin,

Abbreviations: SEA, schistosome egg antigen; MIP-la, macrophage inflammatory protein-l $\alpha$; MCP-1, monocyte chemoattractant protein-1: IL-8, interleukin-8; PBS, phosphate-buffered saline; HPF, high-power fields; HBSS, Hanks' balanced salt solution; CFA, complete Freund's adjuvant; IFA, incomplete Freund's adjuvant; TNF, tumor necrosis factor.

Correspondence: Nicholas W. Lukacs, Ph.D., Dept. of Pathology, Univ. of Michigan Medical School, 1301 Catherine, Ann Arbor, MI 48109-0602.

Received April 10, 1996; revised August 7, 1996; accepted August 8, 1996. 
and RANTES [15]. The C-C family members are of particular interest in the allergic response because there appears to be a strong correlation with the continued expression of $\mathrm{C}-\mathrm{C}$ chemokines and chronic diseases that feature mononuclear and eosinophilic leukocyte recruitment [16]. In particular, eotaxin, MIP-lga, and RANTES may be important in allergic airway responses for several reasons. These proteins have been shown to be chemotactic for monocytes, differentially chemotactic for lymphocyte subsets [17-19], and more importantly, chemotactic for eosinophils [2023]. With the use of the SEA-induced allergic airway model we have previously demonstrated that MIP-1 $\alpha$ plays an important role in eosinophil accumulation in vivo after airway challenge [24].

In this study the direct effect of C-C chemokines in eosinophil accumulation during allergic airway inflammation was examined. The data demonstrated that in vitro eosinophil chemotactic activity in biological lung samples reflected the peribronchial eosinophil accumulation in vivo. Furthermore, the eosinophil chemotactic activity could be nearly abrogated by preincubation of lung samples from allergic mice with a specific anti-MIP-1 $\alpha$ or anti-RANTES antibody, but not anti-MCP-1, in vitro, suggesting that MIP-1 $\alpha$ and RANTES have important roles in mediating eosinophil accumulation in this model.

\section{MATERIALS AND METHODS}

\section{Animals}

Female CBA/J mice purchased from Jackson Laboratories (Bar Harbor, ME) were maintained under standard pathogen-free conditions.

\section{Egg isolation and soluble egg antigen (SEA) protein preparation}

Soluble egg antigens were prepared from acutely $S$. mansoni-infected mice as previously described [25]. Briefly, eggs were isolated from livers of infected mice after a 3-day incubation and ground on ice to release the soluble antigens from the egg. The preparation was then spun in an ultracentrifuge at $100,000 \mathrm{~g}$ for $2 \mathrm{~h}$ and the supernatant collected. The antigens in the supernatant are primarily glycoproteins, which have been characterized as inducing a Th2-type granulomatous response in schistosomiasis $[25,26]$.

\section{Sensitization and induction of the airway response}

To induce a Th2-type response the following procedure was established in normal CBA/J mice as previously described [24]. Briefly, the mice were immunized intraperitoneally with 5000 isolated $S$. mansoni eggs at days 0 and 7 of the protocol. On day 14 the mice were given an intranasal challenge of $10 \mu \mathrm{g}$ of SEA in $10 \mu \mathrm{L}$ of phosphate-buffered saline (PBS) to localize the response to the airway. This initial intranasal challenge with antigen induced little cellular infiltrate into the lungs of the mice upon histological examination. Mice were then rechallenged 6 days later by intratracheal administration of $10 \mu \mathrm{g}$ of SEA in $25 \mu \mathrm{L}$ of sterile PBS or with PBS alone (vehicle). The mice were killed at various times after the intratracheal challenge $(1,8,24,48$, and $72 \mathrm{~h})$ and the lungs inflated and fixed in $10 \%$ buffered formalin. The magnitude of infiltration in both the vehicle control and SEA-challenged mice was examined histologically. Only the SEA-challenged mice displayed a significant inflammatory response, which included neutrophil and eosinophil infiltration as previously described [27].
Morphometric analysis of peribronchial eosinophils

Mice immunized and challenged with SEA or saline vehicle were preserved with $1 \mathrm{~mL}$ of $4 \%$ paraformaldehyde at various time points postchallenge. The fixed lungs were embedded in paraffin and multiple $50-\mu \mathrm{m}$ step sections were differentially stained with Wright-Giemsa for the identification of eosinophils and viewed at $1000 \times$. The individual eosinophils were counted from 100 high-power fields (HPF) per mouse lung at each time point using multiple step sections of lung. To count the eosinophils a strict criteria was followed. The eosinophils counted were in juxtaposition to an airway. This assured the enumeration of only those eosinophils within or immediately adjacent to an airway. The inflammation observed in this model was nearly completely associated with the airway with little or no alveolitis.

\section{Lung homogenates}

Isolated whole-lung tissue was homogenized on ice using a tissue-tearer (Biospec Products, Racine, WI) for $30 \mathrm{~s}$ in $1 \mathrm{~mL}$ of PBS. The resulting supernatant was isolated after a high-speed spin $(10,000 \mathrm{~g})$ and subsequent filtration through a 1.2- $\mu \mathrm{m}$ syringe filter (Gelman Sciences, Ann Arbor, MI). The supernatant was then used in chemotactic assays at a 1:1 ratio with Hanks' balanced saline solution (HBSS).

\section{Isolation of eosinophils}

Eosinophils were elicited by thioglycollate injection into the peritoneum of $S$. mansoni egg antigen-sensitized mice. This protocol induces a pool of circulating eosinophils to be recruited into the peritoneum. After $48 \mathrm{~h}$ the mice were peritoneally lavaged and the cells collected. Cells were suspended in RPMI-1640 supplemented with 5\% fetal calf serum (FCS), 10-5 2-ME, $2 \mathrm{mM}$ sodium pyruvate, $20 \mathrm{mM}$ L-glutamine, and $100 \mathrm{U}$ and $100 \mathrm{mg} / \mathrm{mL}$, respectively, of penicillin and streptomycin. Adherent cell populations were removed by plastic adherence in tissue culture dishes for $1 \mathrm{~h}$. The nonadherent cells (eosinophils and lymphocytes) were collected, cytospinned, and differentially stained, and the percentage of eosinophils counted. This procedure yields approximately $70-80 \%$ eosinophil pure populations to be used in the chemotaxis assays, with the remainder of the cells primarily lymphocytic. The cells can be easily differentiated morphologically on stained chemotaxis filters by nuclei and granular staining techniques described above.

\section{Chemotaxis assay}

Chemotactic assays were performed as previously described [28]. Briefly, $150 \mu \mathrm{L}$ of diluted (1:1) supernatant specimen, recombinant chemokine, or HBSS (GIBCO, Grand Island, NY) were placed in duplicate bottom wells of a blind-well chemotaxis chamber. A 3- $\mu \mathrm{m}$ pore size polycarbonate filter (polyvinylpyrrolidone-free, Nucleopore Corp.) was placed in the assembly and $250 \mu \mathrm{L}$ of peritoneal-elicited murine eosinophil suspension $\left(1 \times 10^{6} / \mathrm{mL}\right)$ was placed in the top chamber. Chemotaxis chamber assemblies were incubated at $37^{\circ} \mathrm{C}$ in humidified $95 \%$ air $/ 5 \% \mathrm{CO}_{2}$ for $75 \mathrm{~min}$. The filters were removed, fixed in absolute methanol, and stained with eosin and counterstained with $2 \%$ toluidine blue (Sigma Chemical). Cells that had migrated through to the bottom of the filter were counted in $10 \mathrm{HPFs}$ (400 or $1000 \times$ magnification). Chemotaxis of eosinophils was expressed as the number of cells per HPF. For neutralization experiments, conditioned media from both SEAand vehicle airway-challenged mice were preincubated with a 1:200 dilution of control, anti-RANTES, anti-MCP-1, or anti-MIP-1 $\alpha$ neutralizing anti-serum for $30 \mathrm{~min}$ at $37^{\circ} \mathrm{C}$, then assayed for cellular chemotactic activity.

\section{Production of antibodies specific for murine C-C chemokines}

Rabbit anti-murine MIP-1 $\alpha$ and MCP-1 antibodies were prepared by multiple-site immunization of New Zealand White rabbits with recombinant murine MIP-1 $\alpha$ or MCP-1 (Genzyme) in complete Freund's adjuvant (CFA). Rabbits were boosted with the appropriate recombinant chemokine in incomplete Freund's adjuvant (IFA). Polyclonal antibodies 
were titered by direct enzyme-linked immunosorbent assay (ELISA) and specifically verified by the failure to cross-react to murine mIL-3, mIL-l $\alpha$, murine tumor necrosis factor (mTNF), mMIP-l $\alpha$, IL-6, mMCP1, mMIP-1 $\beta$, hMCP-1, hIL-8, hRANTES, hMIP-l $\alpha$, hTNF, m-eotaxin, h-eotaxin, and hMIP-1B.

Rabbit anti-murine RANTES was made using a synthetic peptide from the C-terminus end of the murine RANTES sequence and was generously supplied by Bruce Dorherty (Merck, Rahway, NJ). Polyclonal antibodies were titered by direct ELISA and specifically verified by the failure to cross-react to mIL-3, mIL-l $\alpha$, mTNF, mMIP-1 $\alpha$, IL-6, mMCP-1, mMIP-1 $\beta$, hMCP-1, hIL-8, hRANTES, hMIP-1 $\alpha$, hTNF, meotaxin, h-eotaxin, and hMIP-1B. Native murine RANTES is not presently available.

\section{Statistics}

Statistical significance was determined by analysis of variance with $P<$ 0.05 .

\section{RESULTS}

\section{Accumulation of eosinophils around the airways of allergen-challenged mice}

To determine the intensity of peribronchial eosinophil accumulation within the lung, paraffin-embedded lung sections from vehicle or allergen-challenged mice were differentially stained specifically for eosinophils (Fig. 1). Morphometric analysis of the inflamed airways demonstrated an allergen-specific accumulation of eosinophils within challenged lungs. In SEA-challenged animals the eosinophil accumulation could first be observed at $8 \mathrm{~h}$, peaked at $24 \mathrm{~h}$, and was maintained at 48 and $72 \mathrm{~h}$ post-challenge (Fig. 2). In contrast, in vehicle control-challenged mice little or no eosinophil accumulation was observed at any time point. These data demonstrate an antigen-specific accumulation of eosinophils peribronchially similar to previous results in BAL fluid samples from SEA airway-challenged mice [26].

\section{Induction of in vitro eosinophils chemotaxis by $\mathrm{C}-\mathrm{C}$ chemokines}

Previous results have indicated that MIP-1 $\alpha$, eotaxin, and RANTES have chemotactic activity for eosinophils [2023]. To determine the effectiveness and concentration gradient of MIP-1 $\alpha$ and eotaxin on mouse eosinophils, we performed in vitro chemotactic assays using actively elicited

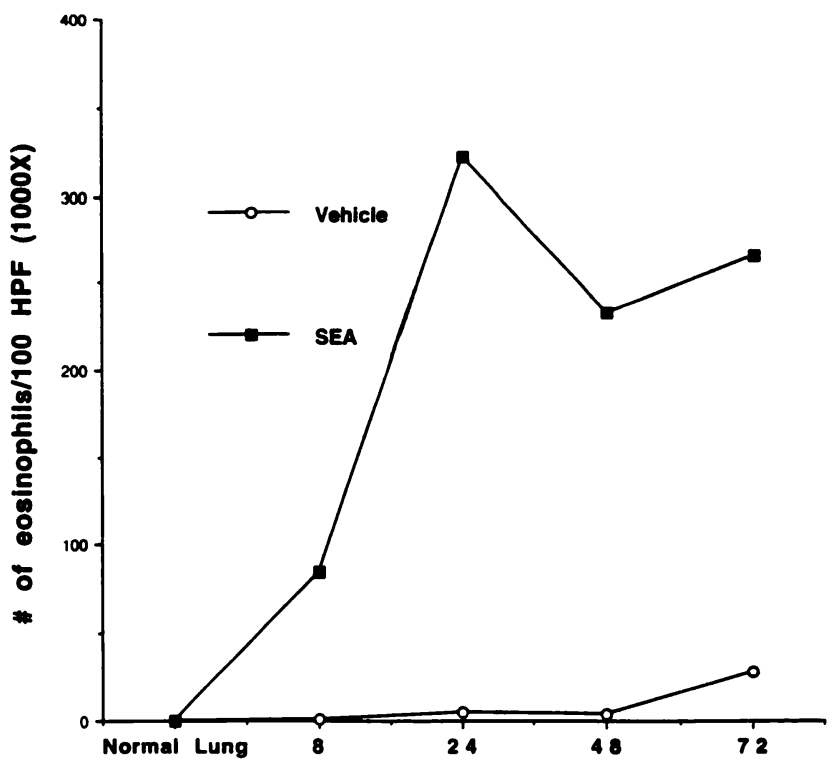

Time After SEA Challenge (Hrs)

Fig. 2. Morphometric analysis of eosinophil accumulation around the airways of mice. Lungs were removed at various time points from mice challenged with either specific allergen (SEA) or vehicle control. Paraffinembedded lungs were specifically stained for eosinophils. Eosinophils directly surrounding or within airways were counted in 100 HPF/ung. Repeat experiments demonstrated similar results.

eosinophils from SEA-sensitized mice. As shown in Figure 3 , MIP-l $\alpha$ induced chemotaxis at $1 \mathrm{ng} / \mathrm{mL}$, peaked at $10 \mathrm{ng} / \mathrm{mL}$, and decreased slightly at $30 \mathrm{ng} / \mathrm{mL}$, whereas eotaxin also demonstrated an increase at $1 \mathrm{ng} / \mathrm{mL}$, but demonstrated only a modest increase at 10 and $30 \mathrm{ng} / \mathrm{mL}$ when compared with MIP-l $\alpha$. When MCP-1, another C-C chemokine, was tested in eosinophil chemotaxis, no chemotactic activity was observed, even at high concentrations (100 ng/mL; data not shown). Murine RANTES is not available for testing and human RANTES did not induce significant chemotaxis in our assays (data not shown). Although it appears that MIP-1 $\alpha$ is more potent, these studies demonstrate that both MIP-1 $\alpha$ and eotaxin can specifically induce murine eosinophil chemotaxis.

Fig. 1. Specific staining of eosinophils accumulated peribronchially in paraffin-embedded lung sections from allergic mice $24 \mathrm{~h}$ after allergen challenge. Lungs were removed at specific time points after allergen (SEA) challenge of mice and specifically stained for eosinophils [magnification $\times 400(A)$; $\times 1000(B)]$.

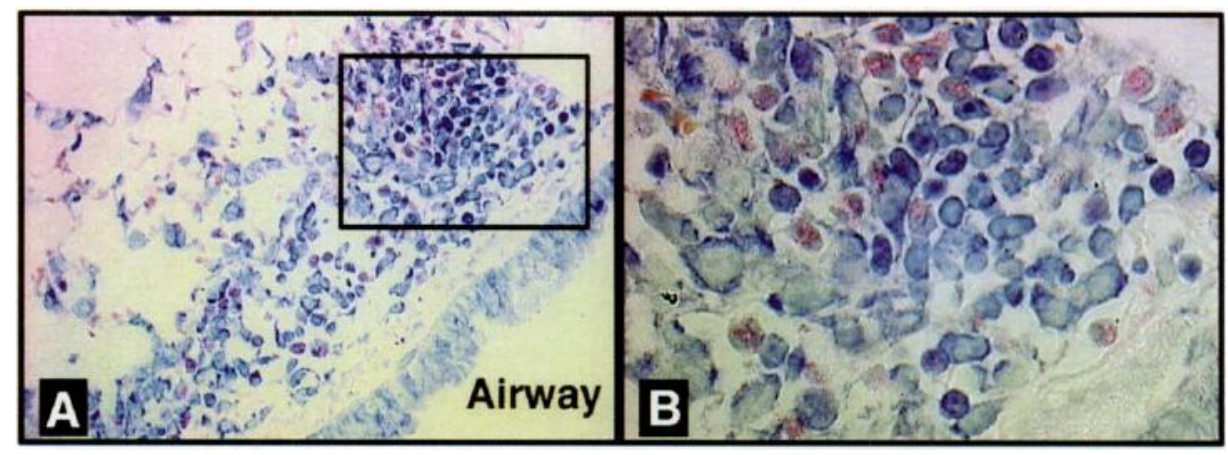




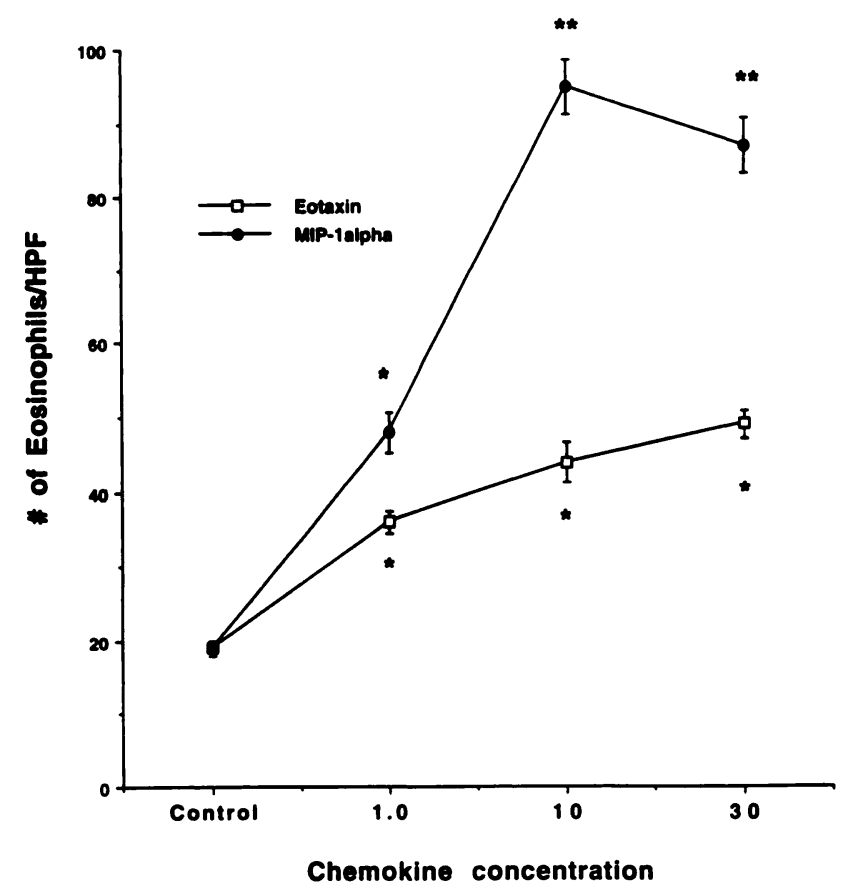

Fig. 3. In vitro eosinophil chemotaxis to various doses of MIP-1 $\alpha$ and eotaxin. Eosinophils were actively elicited from SEA-sensitized mice with thioglycollate and SEA $(10 \mu \mathrm{g} / \mathrm{mL})$ to the peritoneum. Contaminating cell populations were removed from lavage fluid by lysis of red blood cells and plate adherence of macrophages leaving 80-90\% pure population of eosinophils. Chemotaxis assays were performed in modified Boyden chambers with the use of $3-\mu \mathrm{m}$ pore filters. After $1 \mathrm{~h}$ at $37^{\circ} \mathrm{C}$ the filters were removed and differentially stained for eosinophils. Data represents mean $\pm \mathrm{SE}$. Repeat experiments demonstrated similar results. ${ }^{*} P<0.05 ;{ }^{* *} P<0.005$.

\section{Inhibition of allergic lung eosinophil chemotactic activity by neutralization of $\mathrm{C}-\mathrm{C}$ chemokines}

To initially identify the time of peak chemotactic activity in allergic lungs, whole-lung homogenates from various time points post-allergen challenge, $8,24,48$, and $72 \mathrm{~h}$, were utilized for in vitro chemotactic assays. Figure 4 illustrates that eosinophil chemotactic activity was significantly increased at $8 \mathrm{~h}$, peaked at $24 \mathrm{~h}$, and quickly declined in 48- and 72-h whole-lung homogenates. We have previously demonstrated that neutralization of MIP-l $\alpha$ in vivo inhibited eosinophil accumulation within the lungs and airways of allergic mice [24]. To examine whether MIP-1 $\alpha$ and other C-C chemokines had direct effects on eosinophil chemotaxis, control, anti-MIP-1 $\alpha$, anti-RANTES, or antiMCP-1 antibodies were added in vitro just before the chemotaxis assay to the whole-lung homogenates from 8and 24-h untreated SEA-challenged mice (Fig. 5). In these experiments results were observed that demonstrated a significant decrease in eosinophil chemotaxis in both 8and 24-h whole-lung homogenates after treatment with antiMIP-1 $\alpha$ or anti-RANTES, but not anti-MCP-1. Altogether these results indicate that MIP-l $\alpha$ and RANTES are eosinophil chemotactic factors present within the lungs during allergic airway responses and directly contribute to the eosinophil accumulation.

\section{DISCUSSION}

The production of chemokines during allergic airway responses may contribute specifically to the influx of eosinophils. Eosinophils have been implicated as a major effector cell inducing airway injury and subsequent late-phase reactivity in asthmatics $[1,2]$. In this study we were interested in the relative activity of known C-C chemokines on mouse eosinophils. Supporting previous studies, both MIP-l $\alpha$ and eotaxin were found to be active in vitro for eosinophil chemotaxis. Interestingly, MIP-1 $\alpha$ appeared to be more active than eotaxin in our assays. The relative activity of specific C-C chemokines may vary greatly between species and likely explain differences in results found between animal and human cell populations. Using an established model of allergic airway inflammation, we have previously demonstrated that neutralization of MIP-1 $\alpha$ significantly reduced the accumulation of eosinophils in vivo after an allergen challenge [24]. Using this same model we have demonstrated that the accumulation of eosinophils peribronchially in allergic mice correlates to chemotactic activity from lung samples in vitro. Furthermore, the chemotactic activity was specifically attenuated when lung homogenates

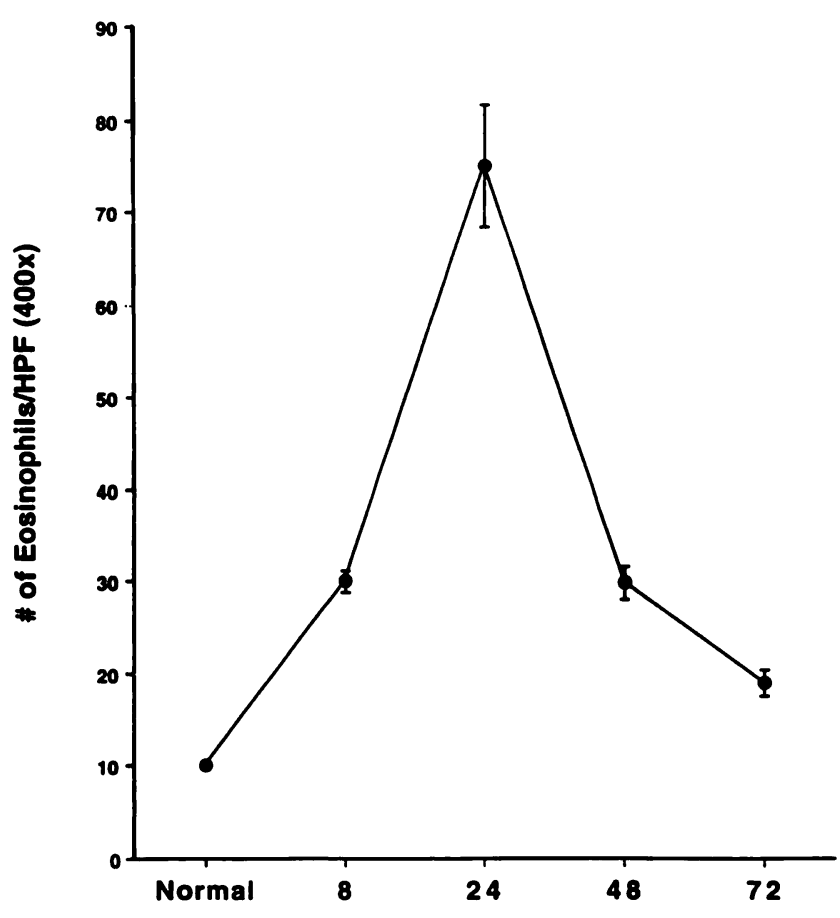

Time After Allergen Challenge (Hrs)

Fig. 4. In vitro eosinophil chemotaxis with whole-ly 'omogenates from allergen-challenged mice. Whole lungs were hon aized in $1 \mathrm{~mL}$ PBS and the supernatant was diluted 1:2 before in vitro chemotactic assays. The homogenates were then used as a chemotaxin in the bottom well of a modified Boyden chamber with a $3-\mu \mathrm{m}$ pore filter and $2 \times$ $10^{5}$ eosinophils. After $1 \mathrm{~h}$ the filters were removed, top side scraped to remove excess eosinophils, fixed, stained, and counted under $\times \mathbf{4 0 0}$ magnification. Data represents mean \pm SE from three different mice at each time point. 

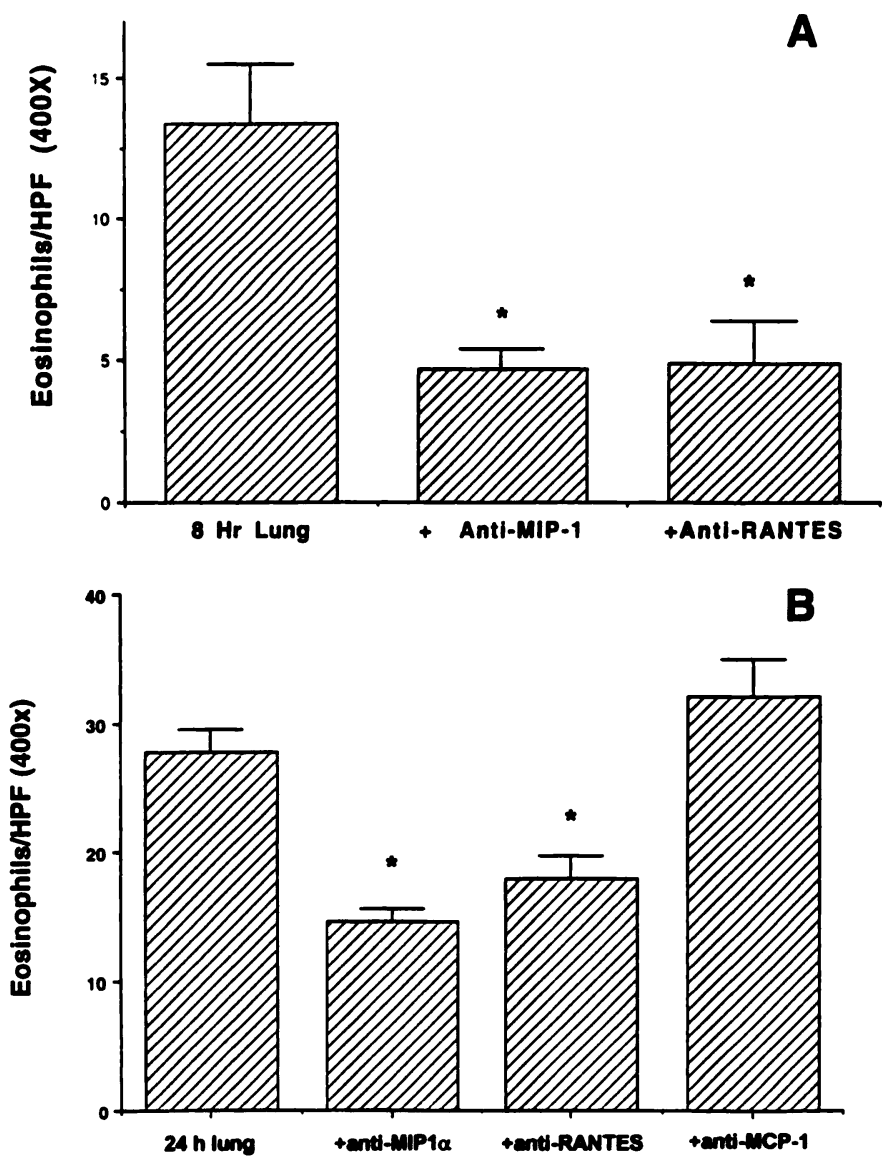

Fig. 5. In vitro eosinophil chemotaxis with whole-lung homogenates indicates a direct role for MIP-1 $\alpha$ and RANTES, but not MCP-1. Whole lungs from 8- (A) or 24-h (B) time points after allergen challenge were homogenized in $1 \mathrm{~mL}$ PBS and the supernatant, diluted 1:2, was preincubated for $30 \mathrm{~min}$ with anti-MIP-1 $\alpha$, anti-RANTES, anti-MCP-1, or control antibody. The homogenates were then used as a chemotaxin in the bottom well of a modified Boyden chamber with a $3-\mu \mathrm{m}$ pore filter with isolated eosinophils. After $1 \mathrm{~h}$ the filters were removed, top side scraped to remove excess eosinophils, fixed, stained, and counted under $\times 400$ magnification. Normal and vehicle-challenged lungs had minimal eosinophil chemotaxis of $3 \pm 1$ and $5 \pm 3$ eosinophils/HPF, respectively. ${ }^{*} P<0.05$.

from allergic mice were pretreated just before chemotaxis in vitro with antibodies specific for MIP-1 $\alpha$. In addition, pretreatment of the lung homogenates with anti-RANTES, but not anti-MCP-1, significantly reduced the chemotactic activity. Altogether, these studies demonstrated that MIP$1 \alpha$ and RANTES during an allergic airway response in mice were directly chemotactic for eosinophils. These results correspond well with in vitro data which demonstrate that MIP-1 $\alpha$ and RANTES, but not MCP-1, are chemotactic for eosinophils. Similar studies may be important to identify potential therapeutic targets for attenuating eosinophil accumulation in and around the airway in human asthma.

A number of steps are required for the migration of eosinophils into tissues from the vascular compartment. The interaction of leukocytes with vascular endothelium is a primary event that requires the expression of endothelial cell-derived adhesion molecules [29-34]. The adhesion molecules facilitate leukocyte spreading on the endothelium, allowing the transendothelial migration of the leukocytes toward chemotactic gradients. In eosinophil migration it appears that VLA-4/VCAM-1 interactions are extremely important because blockage of these interactions attenuates the eosinophil migration [35]. The migration of the eosinophils from the lumen of the vessel into the tissue subsequently requires a chemotactic gradient that can be supplied by a number of potential factors. These factors include inflammatory mediators such as complement split products (C5a), leukotrienes, and platelet-activating factor. However, these substances also have neutrophil chemotactic activity and do not explain the preferential recruitment of eosinophils during asthmatic/allergic responses. Both MIP-l $\alpha$ and RANTES have previously been described as eosinophil chemotactic proteins that are probably responsible for eosinophil accumulation in vivo. For example, the intradermal injection of RANTES into dogs caused the accumulation of eosinophils and mononuclear leukocytes, whereas other chemokines did not [22]. Likewise, a recent publication identified MIP-l $\alpha$ as a major eosinophil chemoattractant in mice [21]. Other members of the C-C chemokine family also have eosinophil chemotactic properties. Eotaxin and MCP-3 have been identified as potent eosinophil chemoattractant proteins and therefore have also been implicated in allergic responses [23, 36]. The detection of eosinophil chemoattractant proteins may serve to identify important targets in inflammation for attenuation of allergic airway diseases. It is likely that a number of these factors are involved in the overall recruitment of eosinophils, however, the identification of preferential utilization of particular factors during allergic airway responses in vivo is crucial.

In addition to the chemokines, other cytokines have demonstrated eosinophil recruitment activity. Lymphocyte chemoattractant factor is produced by $\mathrm{CDB}^{+} \mathrm{T}$ cells, utilizes CD4 molecules on cells, and appears to be an eosinophil chemoattractant in vitro [37]. IL-2, a T cell growth factor, also appears to have eosinophil chemokinetic activity [38], whereas IL-5, an eosinophil maturation and differentiation factor, is not only directly chemotactic for eosinophils, but also has the ability to prime eosinophils for enhanced chemotactic responses to other factors [39]. Overall, the recruitment of eosinophils probably requires several signals for maturation and activation followed by a chemotactic gradient in tissue for the eosinophils to migrate. In the present study we have utilized eosinophils that were actively elicited by thioglycollate and specific antigen (SEA). It is therefore likely that the isolated eosinophils have been exposed to multiple stimuli (IL-2, IL-5, etc.) that allowed maturation and activation of the eosinophils before chemotaxis in vitro. These conditions may be a common circumstance that relates to the effective mechanism(s) of enhanced eosinophil infiltration during chronic allergic responses in vivo.

The results of this study identify MIP-1 $\alpha$ and RANTES, produced locally in the lungs after allergen challenge, as direct chemotactic factors for eosinophils. These data ex- 
tend earlier observations and suggest that MIP-1 $\alpha$ and RANTES are major chemotactic proteins involved in eosinophil recruitment during allergic airway responses. Future studies should identify other factors responsible for eosinophil recruitment and determine the relative contribution each has in the total eosinophil chemotactic activity during the recruitment process.

\section{ACKNOWLEDGMENTS}

This work was supported in part by grants from NIH (AI36302) and the American Lung Association.

\section{REFERENCES}

1. Kay, A. B. (1988) The eosinophil. In Pulmonary Diseases and Disorders, 2nd ed. (A. P. Fishman, ed.) New York, McGraw-Hill, 599-606.

2. Kay, A. B., Corrigan, C. J. (1992) Asthma, eosinophils, and neutrophils. B. Med. Bull. 48, 51-64.

3. Gleich, G. J. (1986) The eosinophilic leukocyte: Structure and function. Adv. Immunol. 39, 177-253.

4. Wang, J. M., Sherry, B., Fivash, M. J., Kelvin, D. J., Oppenheim, J. J. (1993) Human recombinant macrophage inflammatory protein-l $\alpha$ and $\beta$ and monocyte chemotactic and activating factor utilize common and unique receptors on human monocytes. J. Immunol. 150, 3022-3029.

5. Corrigan, C. J., Kay, A. B. (1992) Asthma. Role of T-lymphocytes and lymphokines. Br. Med. Bull. 48, 72-84.

6. Corrigan, C. J., Kay, A. B. (1992) T cells and eosinophils in the pathogenesis of asthma. Immunol. Today 13, 501-507.

7. Del Prete, G. (1992) Human Thl and Th2 lymphocytes: their role in the pathophysiology of atopy. Allergy 47, 450-455.

8. Gratziou, C., Carroll, M., Walls, A., Howarth, P. H., Holgate, S. T. (1992) Early changes in $\mathrm{T}$ lymphocytes recovered by bronchoalveolar lavage after local allergen challenge of asthmatic airways. Am. Rev. Respir. Dis. 145, 1259-1264.

9. Kay, A. B. (1991) T lymphocytes and their products in atopic allergy and asthma. Int. Arch. Allergy Appl. Immunol. 94, 189-193.

10. Robinson, D. S., Hamid, Q., Ying, S., Tsicopoulos, A., Barkans, J., Bentley, A. M., Corrigan, C., Durham, S. R., Kay, A. B. (1992) Predominant TH2like bronchoalveolar T-lympocyte population in atopic asthma. N. Engh J. Med. 326, 298-304.

11. Romagnani, S., Maggi, E., Parronchi, P., Macchia, D., Piccinni, M. P., Ricci, M. (1991) Increased numbers of Th2-like CD4 + T cells in target organs and in the allergen-specific repertoire of allergic patients. Possible role of IL-4 produced by non-T cells. Int. Arch. Allergy Apph. Immunol. 94, 133-136.

12. Walker, C., Virchow, J. C., Jr., Bruijnzeel, P. L., Blaser, K. (1991) T cells and asthma. II. Regulation of eosinophilia of asthma by $\mathrm{T}$ cell cytokines. Int. Arch. Allergy Appl. Immunol. 94, 248-250.

13. Zhang, X., Polla, B., Hauser, C., Zubler, R. H. (1992) T cells from atopic individuals produce IgE-inducing activity incompletely blocked by antiinterleukin-4 antibody. Eur. J. Immunol. 22, 829-833.

14. Gavett, S. H., Chen, X., Finkleman, F., Wills-Karp, M. (1994) Depletion of murine CD4 + T lymphocytes prevents antigen-induced airway hyperreactivity and pulmonary eosinophilia. Am. J. Respir. Cell Mol. Biol. 10, 587-593.

15. Schall, T. J. (1991) Biology of the RANTES/SIS cytokine family. Cytokine 3, 165-183.

16. Oppenheim , J. J., Zachariae, C. O. C., Mukaida, N., Matsushima, K. (1991) Properties of the novel proinflammatory "intercrine" cytokine family. Annu. Rev. Immunol. 9, 617.

17. Davatelis, G., Tekamp-Olson, P., Wolpe, S. D., Hermsen, K., Luedke, C., Gallegos, C., Coit, D., Merryweather, J., Cerami, A. (1988) Cloning and characterization of a cDNA for murine macrophage inflammatory protein (MIP), a novel monokine with inflammatory and chemokinetic properties. J. Exp. Med. 167, 1939-1944.

18. Taub, D. D., Conlon, K., Lloyd, A. R., Oppenheim, J. J., Kelvin, D. J. (1993) Preferential migration of activated CD4 ${ }^{+}$and CD8 + T cells in response to MIP-la and MIP-lb. Science 26, 355-358.

19. Wolpe, S. D., Davatelis, G., Sherry, B., Beutler, B., Hesse, D. G., Nguyen, H. T., Moldawer, L. L., Nathan, C. F., Lowry, S. F., Cerami, A. (1988) Macrophages secrete a novel heparin-binding protein with inflammatory and neutrophil chemokinetic properties. J. Exp. Med. 167, 570-581.

20. Rot, A., Krieger, M., Brunner, T., Bischoff, S. C., Schall, T. J., Dahinden,
C. A. (1992) RANTES and macrophage inflammatory protein $1 \alpha$ induce the migration and activation of normal human eosinophil granulocytes. $J$. Exp. Med. 176, 1489-1495.

21. Post, T. W., Boxic, C. R., Rothenberg, M. E., Luster, A. D., Gerand, N., Gerard, C. (1995) Molecular characterization of two murine eosinophil b chemokine receptors. J. Immunol. 155, 5299-5305.

22. Meurer, R., Van Riper, G., Feeney, W., Cunningham, P., Hora, D., Springer, M. S., MacIntyre, D. E., Rosen, H. (1993) Formation of eosinophilic and monocytic intradermal inflammatory sites in the dog by injection of human RANTES but not human monocyte chemoattractant protein 1 , human macrophage inflammatory protein 1 alpha, or human interleukin 8. J. Exp. Med. 178, 1913-1921.

23. Jose, P. J., Griffiths-Johnson, D. A., Collins, P. D., Walsh, D. T., Moqbel, R., Totty, N. F., Truong, O., Hsuan, J. J., Williams, T. J. (1994) Eotaxin: a potent eosinophil chemoattractant cytokine detected in a guinea pig model of allergic airways inflammation. J. Exp. Med. 179, 881-887.

24. Lukacs, N. W., Strieter, R. M., Shaklee, C. L., Chensue, S. W., Kunkel, S. L. (1995) Macrophage inflammatory protein-la influences eosinophil recruitment in antigen-specific airway inflammation. Eur. J. Immunol. 25, 245-251.

25. Chensue, S. W., Warmington, K. S., Lukacs, N. W., Lincoln, P. M., Burdick, M. D., Strieter, R. M., Kunkel, S. L. (1995) Monocyte chemotactic protein expression during schistosome egg granuloma formation: Sequence of production, localization, contribution, and regulation. Am. J. Pathol. 146 , 130-138.

26. Grzych, J. M., Pearce, E., Cheever, A., Caulada, Z. A., Caspar, P., Henry, S., Lewis, F., Sher, A. (1991) Egg deposition is the major stimulus for the production of Th2 cytokines in murine schistosomiasis mansoni. J. Im. munol. 146, 1322-1329.

27. Lukacs, N. W., Strieter, R. M., Chensue, S. W., Kunkel, S. L. (1994) Interleukin-4-dependent pulmonary eosinophil infiltration in a murine model of asthma. Am. J. Respir. Cell Mol. Biol. 10, 526-532.

28. Standiford, T. J., Rolfe, M. W., Kunkel, S. L., Lynch, J. P., III, Burdick, M. D., Gilbert, A. R., Orringer, M. B., Strieter, R. M. (1996) Macrophage inflammatory peptide-l alpha expression in interstitial lung disease. J. Immunol. in press.

29. Luscinskas, F. W., Cybulsky, M. I., Kiely, J. M., Peckins, C. S., Davis, V. M., Gimbrone, M. A., Jr. (1991) Cytokine-activated human endothelial monolayers support enhanced neutrophil transmigration via a mechanism involving both endothelial-leukocyte adhesion molecule-l and intracellular adhesion molecule 1. J. Immunol. 146, 1617.

30. Bevilacqua, M. P., Pober, J. S., Wheeler, M. E., Cotran, R. S., Gimbrone, M. A., Jr. (1985) Interleukin 1 acts on cultured human vascular endothelium to increase the adhesion of polymorphonuclear leukocytes, monocytes, and related leukocyte cell lines. J. Clin. Invest. 76, 2003.

31. Dustin, M. L., Rothlein, R., Bhan, A. K., Dinarello, C. A., Springer, T. A. (1986) Induction by IL-l and interferon-gamma: tissue distribution, biochemistry, and function of a natural adherence molecule (ICAM-1). J. Immunol. 137, 245.

32. Hakkert, B. C., Kuijpers, T. W., Leeuwenberg, J. F., van Mourik, J. A., Roos, D. (1991) Neutrophil and monocyte adherence to and migration across monolayers of cytokine-activated endothelial cell: the contribution of CD18, ELAM-1, and VLA-4. Blood 78, 2721.

33. Carlos, T., Kovach, N., Schwartz, B., Rosa, M., Newman, B., Wayner, E., Benjamin, C., Osborn, L., Lobb, R., Harlan, J. (1991) Human monocytes bind to two cytokine-induced adhesive ligands on cultured human endothelial cells: endothelial-leukocyte adhesion molecule-l and vascular cell adhesion molecule-l. Blood 77, 2266.

34. Zimmerman, G. A., Prescott, S. M., McIntyre, T. M. (1992) Endothelial cell interactions with granulocytes: tethering and signaling molecules. Immunol. Today 13, 93.

35. Schleimer, R. P., Sterbinsky, S. A., Kaiser, J., Bickel, C. A., Klunk, D. A., Tomioka, K., Newman, W., Luscinskas, F. W., Gmbrone, M. A., Jr., McIntyre, B. W., Bochner, B. S. (1993) IL-4 induces adherence of human eosinophils and basophils but not neutrophils to endothelium. Association with expression of VCAM-1. J. Immunol. 148, 1086.

36. Dahinden, C. A., Geiser, T., Brunner, T., von Tscharner, V., Caput, D., Ferrara, P., Minty, A., Baggiolini, M. (1994) Monocyte chemotactic protein 3 is a most effective basophil- and eosinophil-activating chemokine. J. Exp. Med. 179, 751-760.

37. Rand, T. H., Cruikshank, W. W., Center, D. M., Weller, P.F. (1991) CD4mediated stimulation of human eosinophils: lymphocyte chemoattractant factor and other CD4-binding ligands elicit eosinophil migration. J. Exp. Med. 173, 1521-1528.

38. Rand, T. H., Silberstein, D. S., Kornfeld, H., Weller, P. F. (1991) Human eosinophils express functional interleukin 2 receptors. J. Clin. Invest. 88, 825-832.

39. Sehmi, R., Wardlaw, A. J., Cromwell, O., Kurihara, K., Waltmann, P., Kay, A. B. (1992) Interleukin-5 selectively enhances the chemotactic response of eosinophils obtained from normal but not eosinophilic subjects. Blood 79, 2952-2959. 